\title{
MECANISMOS DE OPRESSÃO: UMA QUESTÃO DE GÊNERO
}

Vera Regina Waldow ${ }^{1}$

RESUMO: Visão geral da opressão sofrida pela mulher e da relação desta opressão com a Enfermagem. Apresenta a idéia da Enfermagem como grupo oprimido, e analisa alguns comportamentos característicos de grupos oprimidos e a traqnsmissão da opressão na Enfermagem. São apresentadas também algumas idéias sobre feminismo e suas conexões com a Enfermagem. O despertar de conscientização é considerado de grande importância para a libertação da mulher no sentido de criar um novo mundo social, bem como um novo mundo de Enfermagem.

DESCRITORES: Ocupações em saúde; Enfermeiras; Mulheres; Discriminação (psicologia).

\section{MECANISMS OF OPRESSION: A GENDER ISSUE}

ABSTRACT: Na overview of woman's oppression and this relation to the nursing profession. Nursing, considered as an oppressed group, is discussed and how oppressed group behaviors have been transmited through the nursing scenario. The article presents some ideas about feminism and its linkage to nursing. Conciousness-raising is considered of great importance to woman's liberation, and for creating a new world as well as a new nursing world.

DESCRIPTORS: Nurses; Women; Helath occupations; discrimination (psichology).

\footnotetext{
${ }^{1}$ Enfermeira pesquisadora pelo CNPQ com o projeto Cuidar/ Cuidado, vinculado ao Programa Integrado de Pesquisa Cuidando \& Confortando, encaminhado em julho de 1996.
} 


\section{INTRODUÇÃO}

O termo opressão pode apresentar diferentes significados, de acordo com diferentes discursos e situações já que a opressão não ocorre sob o mesmo grau e na forma das sociedades. De acordo com Young (1988, p.271), todas as pessoas oprimidas compartilham "alguma inibição em sua habilidade para desdenvolver e exercitar suas capacidades e expressar suas necessidades, pensamentos e sentimentos".

Mulheres têm sido discriminadas profissionalmente, o que consiste em instrumento de opressão. Esta discriminação, todavia, é mascarada, ou seja, não é exercida de forma explícita.

Existem vários tipos de opressão sobre diferentes grupods, por exemplo: negros, homossexuais, mulheres, idosos, índios, pobres, trabalhadores, deficientes físicos e mentais, entre outros. E nesses grupos: exploração, marginalização, falta de poder, imperialismo cultural e violência. A maioria dos grupos citaods como oprimidos experimentaram mais de uma dessas formas, e alguns experimentaram-nas todas.

Em relação às mulheres, Young refere que elas estão sujeitas à exploração baseada em gênero*, falta de poder, imperialismo cultural e violência.

A opressão das mulheres não se dá simplesmente por uma desigualdade de poder, de status, e de riqueza resultantes de exclusão das mulheres de atividades priviliegiados exercidas pelos homens. Para Young (1988), a liberdade, o poder, o status e a auto-realização dos homens são exatamente possíveis porque as mulheres trabalham para eles. Assim, a exploração baseada em gênero inclui dois aspectos: a transferência do sustento e da energia sexual para o homem.

Tomando-se a concepção marxista da exploração, as mulheres são trabalhadoras assalariadas, cujo trabalho doméstico é uma forma de exploração de classe nas sociedades capitalistas. $\mathrm{O}$ trabalho feminino é um trabalho invisível, não reconhecido. Como grupo, as mulheres experimentam um forma específica de exploração de gênero e tanto público como privado, seu trabalho beneficia a status e satisfaz ou conforta outros, em geral homens.

Lewin (1980, p.46) ao comentar a participação da mulher no sistema produtivo refere que "o emprego de mão-de-obra feminina tem sido considerado extremamente vantajoso quando se elabora a equação de custos de determinadas mercadorias, porque ela se sujeita a perceber remuneração inferior, sobretudo

\footnotetext{
* A idéia de gênero, como tem sido concebida principalmente na literatura feminista, refere-se àqueles aspectos culturais de conotações de sexo, socialmente constrtuídos (Apple, 1987) e que segundo Scott (1990), traduzem um modo de dar significado às relações de poder.
}

devido à sua menor qualificação técnica e á sua baixa capacidade rerivindicativa, resultante de condicionamentos sócio-culturais da sociedade".

Profissões dita femininas, em geral, não usufruem de poder. Falta de status, de autonomia de remuneração e de reconhecimento são queixas comuns dessas profissões, mesmo quando exercidas por um número expressivo de mulheres, que executam funções de relevância, como é o caso das enfermeiras, professoras, assistências sociais, nutricionistas, bibliotecárias, etc. (FERRETTI, 1976; LEWIN, 1980).

Um fato inegável é o de que, segundo coloca Lewin (op.cit, p.59), a ocupação de cargos de maior prestígio e de melhor remuneração por parte dos homens é fruto de um diversificação no sistema econômico, técnico - científico, cultural e de estado. Essa ocupação "processa-se sem prejuízo para o funcionamento do conjunto social, dada a existência da disponibilidade feminina para se inserir nos espaços vazios".

O imperialismo cultural refere-se à universalização da experiência e da cultura de um grupo, estabelecida como norma. Em geral, consiste na predominância da cultura dominante que oprime e determina esterótipos a grupos que se desviam do "normal" e que são considerados "inferiores" e/ ou "diferentes". É o caso de homossexuais, nativos, judeus, e outros que na expressão das suas culturas, são discriminados pelos grupos dominantes. Os rótulos e papíes atribuídos aos grupos que sofrem esse tipo de imperialismo cultural são internalizados, muitas vezes, e não são contestados.

Historicamente, as mulheres têm desempenhado comportamento de inferioridade e de dependência em relação aos homens, e alguns dos estereótipos têm sido tradicionalmente perpetuados, tias como o da maternidade, de esposa, de docilidade, de obediência, de prestar carinho e conforto, de símbolo sexual, etc. A erotização da mulher como objeto de sedução e prazer, bem como a mitificação do papel de mãe, constituem um processo de controle social determinado por um poder dominante. Esses mitos, na ideologia de uma sociedade de classes, "determinam a condição da mulher fundamentando-se, sociológica e culturalmente, na categoria do específico feminino" (LOPES, 1987, p. 144).

Certos grupos estão sob constante ameaça de violência e, segundo Young (1988), alguns autores a explicam como instrumento coercitivo de grupos motivados pelo desejo de manterem privilégios e dominação. As mulheres têm sido um dos grupos vitimados por violência e abuso corporal e mental na história, durante milênios.

\section{COMO A OPRESSÃO ATUA SOBRE NÓS}

Roberts (1983) introduziu a idéia de a Enfermagem se caracterizar por um "grupo de comportamento oprimido". Heidin (1986) e Waldow (1996) no Brasil, 
também realizaram estudos que confirmam a idéia de Roberts. A autora apresenta alguns tipos de opressão correntes na literatura, e como os mecanismos de opressão atuam em diferentes grupos nas sociedades.

Uma das explicações atribuídas à relação entre opressores e oprimidos, é o fato de grupos subordinados se comportarem como hospedeiros, ou seja, viverem uma dualidade, na qual "ser é parecer e parecer é parecer com o opressor" (Freire, 1978, p.32-33). Este autor caracteriza e explica este fenômeno como "aderência" do oprimido ao opressor. A tendência é a de internalizar normas e valores prescritos pelo opressor e acreditar que, sendo igual ao opressor, alcançará o poder. Esse comportamento é inconsciente e segundo Freire (op. Cit, p.35)

os oprimidos, que introjetam a "sombra" dos opressores e seguem suas pautas, temem a liberdade na medida em que esta, implicando na expulsão desta sombra, exigiria deles que "preenchesse" o "vazio" deixado pela expulsão, com outro "conteúdo" - o da sua autonomia.

Alguns grupos de oprimidos. Conforme explica Roberts, (1983), na ânsia de se tornarem mais poderosos, tentam assimilar valores e tornarem-se semelhantes ao opressor. Isto provoca um provoca um processo de marginalização, pois o grupo, ou indivíduo, não pertence nemk ao grupo de oprimidos, tampouco ao dos opressores levando, por conseguinte, a uma ausência de identidade cultural. Os grupos oprimidos apreserntam alguns traços comuns de personalidade que se caracterizam por auto aversão e baixa auto-estima que, por sua vez, favorecem à continuidade do ciclo de dominação e subordinação.

Outro aspecto levantado por Roberts (op. cit.) é o de que a pessoa oprimida, ao sentir-se agressiva contra o opressor, não e capaz de expressar sua agressividade diretamente. Esse comportamento provoca, por sua vez, uma "violência horizontal", na qual existe um conflito dentro do grupo oprimido, resultado da inabilidade de o grupo revoltar-se contra o dominador, e que reverte em agressão dentro do próprio grupo. À semelhança de alguns grupos oprimidos, profissionais de Enfermagem têm exibido problemas entr si como grupo. Existe uma evidente falta de coesão e união entre a catgoria de Enfermagem como um todo.

Schirger (1978) apresenta outro aspecto, que é o do conceito da pseudo - inocência, inspirado no trabalho de Rollo May. A pseudo - inocência é uma inocência infantil e ingênua, na qual os riscos reais não são enfrentados. Existe um propósito inconsciente de fechar os olhos à realidade, e persuadir-se de que não há perigo. Desta forma, o indivíduo torna-se fraco, incapaz e sem poder. Consequentemente, ao rejeitar o poder, o indivíduo não pode ser responsável pelo que ele não tem, tornanado-se portanto inseguro e podendo, neste caso, culpar a outros por seus desenganos e insucessos. Essa circunstância na qual o indivíduo não reconhece seu poder nem lhe dá azo, negando a realidade, resulta em apatia e auto destruição.

\section{COMO A OPRESSÃO É VEICULADA}

O relacionamento de dominação - submissão é um velho problema que tem sido reforçado por mecanismos de interesse dominante que transmitem cultura e valores percebidos como verdades inquestionáveis, mesmo que sejam mitos e não realidade.

A palavra opressão não significa tirania, mas sim refere-se a fenômeno sistêmico e estrutural. A opressão é sistematicamente reproduzida nas principais instituições políticas, econômicas e culturais (YOUNG, 1988).

Ashley (1976, p.25) refere que

o cuidado da saúde não pode ser adequadamente compreendido sem um exame do papel da mulher em prover cuidado. A Enfermagem, como uma profissão de mulheres, tem sido oprimida por um século, e muitos de seus problemas meramente refletem as atitudes da sociedade para com as mulheres em geral.

A autora também chama a atenção para a responsabilidade de o público e os educadores observarem e considerarem os perigos inerentes nas formas de educação, que enfatizam apenas as necessidades de serviço das instituições de saúde definidas por administradores e médicos e que restringem a atuação da enfermagem.

A enfermagem no Brasil tem sido constantemente subjugada pelos interesses dominantes. Suas lideranças, por meio das escolas de Enfermagem e da Associação Brasileira de Enfermagem têm contribuído, até recentemente, para um comportamento de grupo oprimido ao desempenharem o papel de "intelectuais orgânicos"** das classes dominantes.

O forte domínio e poder da religião, representados no brasil pela Igreja Católica, contribuiu também para a reprodução e propagação de princípios de subjugação e passividade. No caso, a mulher - ser inferior - foi educada para ser casta, submissa, obediente, do lar, servindo ao marido, aos filhos, à Igreja e ao Estado.

Outro aspecto que está vinculado ao condicionamento social de sexo, ou seja, da enfermagem como profissão feminina nas esferas de produção capitalista, caracteriza sua condição de assalariada, e reproduz a divisão de classes representada pela divisão interna entre trabalho intelectual e trabalho manual (SILVA, 1986) nesse sentido, Nakamae (1987) aponta, de forma enfática, a questão da divisão entre trabalho manual e trabalho intelectual, ou seja, de oposição entre o saber e o fazer na enfermagem, dentro de uma sociedade dividida em classes antagônicas. A verdadeira função da Enfermagem, ou seja, o cuidado direto, embora enfatizado pelas escolas, não é desempenhado na 
realidade. Segundo Nakamae, portanto, a real função é a de direção, de administração, portanto de cuidado indireto.

Segundo Nakamae (op cit.), a superação das contradições estruturais implica a transformação da própria sociedade. Nesse sentido, as Escolas de Enfermagem poderiam contribuir de forma a propiciar um tipo de ensino que conduzisse a uma práxis transformadora.

Lopes (1987) e Loyola (1987) ressaltam em seus trabalhos os aspectos de docilidade e subalternidade das enfermeiras, e evidenciam a origem desses comportamentos como sendo traqdicionalmente reproduzidos nas atitudes e comportamentos de professores das escolas de enfermagem. A atitude autoritária e fechada das escolas de enfermagem tem por um lado oprimido e, por outro lado, transmitido comportamentos de grupo oprimido às alunas.

\section{LIBERAÇÃO DE UMA CONDIÇÃO OPRIMIDA}

Roberts (1983) menciona que as enfermeiras tem internalizado os valores dos médicos, fato bem evidenciado pelo enfoque da maioria das teoristas de enfermagem que tem sido influenciadas, de forma marcante, pelo modelo tecnicista da medicina.

As enfermeriras têm também sido designadas como "auxiliares de médicos", o que permite uma atitude de domínio e de desvalorização. A falta de identidade e sua pouca representatividade perante o público têm sido também responsáveis pela distorcida imagem da profissão na sociedade, além dos conhecidos estereótipos atribuídos à enfermeira, e em geral estereótipos relacionados à condição feminina.

A falta de participação em organizações profissionais evidencia, segundo Roberts (op cit.), a falta de orgulho em relação à profissão. Isto impede que as enfermeiras queiram participar de organizações e asociar-se a elas. Lopes (1987) coloca como impecilhos à sua participação a alienação, a falta de tradição política da mulher, a falta da consciência de classe, a acomodação, entre outros.

O modelo da "administradora eficiente", veiculada pelas famosas teorias de Taylor e Fayol em prol da produtividade e desempenho ainda persistem. Este enfoque conduz a uma situação que privilegia a instituição em termos de produtividade, em detrimento das necessidades do consumidor (paciente) e da própria Enfermagem, impediando-a de assumir sua verdadeira razão profissional. Essa atividade de zelar pelos bens da casa, mantendo-a limpa e de forma barata, dirigindo os empregados, nada mais é

\footnotetext{
** A definição desta categoria fornecida por Gramsci (in GERMANO, p. 111) caracteriza-se por uma posição e/ou função ocupada numa determinada classe ou categoria e que representa os interesses de uma ideologia dominante. Em geral, atende às aspirações da classe à qual estes intelectuais pertencem organicamente.
}

do que uma atribuição doméstica. Esse quadro caracteriza tipicamente a enfermeira como a seguidora de ordens, mantendo a "casa" (hospital) limpa, as "crianças" (pacientes) confortáveis, para o "marido" ou "proprietário" (médico, administrador), uma tarefa barata desempenhada por uma serviçal obediente, trabalhadora, amorosa e acrítica.

O papel de administradora perde sua importância quando exercido apenas como gerência e, por outro lado, desmereceo significado do cuidar, bem como reproduz a divisão social dentro do ambiente de trabalho. Recentemente teoristas na Enfermagem têm aplicado o conceito de cuidar, no qual estão implícitas as idéias de ideal moral (Watson, 1988), de poder (Benner, 1984) e de comportamento (LEININGER, 1981; 1991).

Para Watson (op cit.) o cuidar requer compromisso pessoal, social, moral e espiritual da enfermeira, comprometimento da profissional com os outros e consigo mesma.

Benner (op cit.) sugere a idéia de cuidar com poder e identifica seis quaidades de poder relacionados ao cuidado prestado pelas enfermeiras que são: poder de transformação, de integração, de proteção, de restauração, de participação e afirmação, de resolução de problemas.

Para Leininger (op cit.), o cuidado é o foco central, dominanate e unificador da Enfermagem. A autora distingue cuidado em geral de cuidado profissional e desenvolve um modelo conceptual de cuidado transcultural, usando uma abordagem etnocientífica.

O modelo comportamental ou "behavorista" no ensino de Enfermagem, propagado pelo modelo curricular de Tyler (1949), também pode ser apontado como outro determinante de grande influência na formação tecnicista da enfermeira. Esse modelo focaliza objetivos comportamentais, portanto preocupa-se com o produto e não com o processo em termos de ensino. Os currículos de Enfermagem inspirados nesse modelo, cujo valor e utilidade no ensino em determinada época, não pode ser negado, enfatizam listas de tarefas e procedimentos que as alunas devem cumprir. Nesse aspecto, o que se pretende destacar é a importância e ênfase dada à técnica, ao comportamento, à aparência, à objetividade, e que parecem reforçar as idéias masculinas positivistas, e que a enfermagem parece ter assimilado e reproduzido. Esses comportamentos que a enfermagem, em sua expressão dita feminina, que tem sido enfatizada e propagada, têm sido responsáveis pela série de contradições que conflitam com a sua prática.

A luta pela desopressão implica a tomada de consciência crítica da opressão, e que é buscada na práxis. A práxis, segundo Freire, (1978) é reflexão e ação por parte dos indivíduos, homens e mulheres, sobre o mundo com o fim de transformá-lo.

A conscientização de nossa condição de opressão parece já ser um passo para a libertação.

Schirger (1978) afirma que as enfermeiras, e somente por meio de uma introspecção interna. Esta introspecção é 
no sentido de se questionar e de se olhar no espelho e tentar aprender a conhecer, entender e aceitar suas fraquezas, frustrações, talentos e capacidades. É tornar-se consciente de si e, nesse sentido, mais uma vez, de se tornar consciente de sua condição de ser oprimido.

Esse desvelamento, esse autoconhecimento levam a diminuir o temor de arriscar-se à independência, possibilitando o assumir posições mais agressivas. Tal fato propicia a conscientização de seu próprio poder e esse processo torna as mulheres enfermeiras mais participativas e habilitadas a desenvolver ação política no sentido de efetuar mudanças no sistema de cuidado da saúde.

Roberts (1983) sugere que após as enfermeiras reconhecerem a existência de opressão e analisarem os seus quês e porquês de forma madura, as atuais lideranças e paradigmas devem ser questionados. Sugere também o incientivo ao diálogo entre enfermeiras de forma que logrem uma mudança nas prioridades, dirigida, contudo, para favorecer os interessews da categoria como um todo.

A comunidade de enfermagem deve, em conjunto, redescobrir sua herança cultural e recriar nova cultura baseada em princípios de unidade e integridade, como sugere o processo feminista de Wheeler e Chinn (1991). Esse processo trata de uma práxis feminista, conceptualizada sob várias formas de poder que leva á unidade, á justiça e á paz. As formas de poder idealizadas Wheeler e Chinn são derivadas de uma perspectiva que valoriza as mulheres e suas realidades, juntamente com suas idéias acerca de como o mundo deveria ser.

FEMINISMO E ENFERMAGEM: a necessidade de criar uma identidade

Existem ligações importantes entre a enfermagem e o feminismo, e segundo Chinn e Wheeler (1985), a enfermagem só tem a beneficiar-se de uma compreensão de teoria feminista, a qual oferece um quadro de referências para examinar a enfermagem sob o ponto de vista histórico, político e pessoal.

Os significados e conteúdos do feminismo não são uniformes mas, de modo geral, o feminismo apóia a mulher, critica o pensamento masculino, desafia sistemas patriarcais e enfoca a criação de amor e auto - respeito entre mulheres.

Para Ramazanoglu (1989), as versões sobre o feminismo apresentam algumas característicasem comum, que resumidamente podem ser colocadas da seguinte maneira:

- no relacionamento homem - mulher, a mulher é subordinada ao homem, relacionamento que deve sofrer mudanças;

- o feminismo desafia e questiona muitas das tradicionais verdades e idéias impostas como naturais e normais bem como a história e o futuro da humanidade;

- o feminismo é um conjunto de idéias que constituem práticas políticas visando à transformação do mundo; - as práticas feministas são provocativas e englobam grupos de atuação de despertar de conscientização (conciousness - raising), aluta pela separação em relação aos homens, reivindicações organizadas em favor da liberdade civil e do poder econômico e político;

- as propostas feministas de mudança sempre encontram resistência que, por sua vez, variam em força e natureza;

- o feminismo questiona o que as mulheres querem dizer por conhecimento e porque algumas formas de conhecimento são mais válidas que as outras. $\mathrm{O}$ feminismo implica uma crítica radical da razão, ciência e teoria social que levanta sérias questões sobre como conhecemos o que pensamos conhecer.

De acordo com Ramazanoglu (op cit.), a principal contradição no movimento do novo feminismo é entre as diferentes escolas de pensamento feminista e dos diferentes escolas de pensamento feminista e dos diferentes estágios da prática política feminista.

A visão mais tradicional é o feminismo liberal. Esta visão reivindica a igualdade de direitos e oportunidades por parte das mulheres em relação aos homens. O feminismo liberal presume que a mulher sofre injustiças em razão de seu sexo, e não questiona muito as causas das desigualdades, ou seja, não identifica as relações entre os sexos como relações específicas de poder (Ramazanoglu, 1989). (...)

A enfermagem tem um novo desafio, que é o de criar sua identidade, talvez a primeira, pessoal e política. É o desafio para criar a sua revolução.

A enfermagem tem dois passos a tomar, o de conscientização de sua condiução oprimida e o de conscientização para a mudança. Essa mudança implicará um processo de transformação interna, de sua prática que é fundamentalmente conquistada pelo conhecimento e reflexão crítica de seu existir. $\mathrm{O}$ autoconhecimento e o conhecimento e compromisso da profissão como coletividade deve ser iniciado. Apenas após uma reflexão e mudança de sua prática, a enfermagem será capaz de reverter sua imagem e conquistar seu espaço.

Deixem as vozes das mulheres,

de todas as mulheres

serem ouvidas.

Mulheres sofridas, batidas, oprimidas,

silenciadas.

Que viveram um mundo e sentiram uma vida

vida sofrida, batida, oprimida,

silenciada.

Deixem as vozes das mulheres poderem

SER

e PODER contar e cantar

em verso e em prosa,

nas ruas, nas praças, nas salas de aula, 
em casa, em comícios, em todo lugar.

Em qualquer lugar.

deixem as mulheres revelar

suas histórias, seus segredos, seus sentimentos, suas realidades, seus eus

o Público e o Privado

o Forte e o Fraco

o Bom e o Mau

o Feio e o Bonito

deixem as vozes das mulheres

possibilitarem a luta por um novo mundo,

UNIDAS.

\section{REFERÊNCIAS}

1. APPLE, M. Relações de classe e de gênero e modificações no processo de trabalho docente. Cadernos de pesquisa, São Paulo, n. 60, p. 4- 14, fev. 1987.

2. ASHLEY, A.A. Hospitals, paternalism and the role of the nurse. New York: Teachers College press, 1976.

3. BENNER, P. From novice to expert: excellence and power in clinical nursing practice. Menlo park: Addison - Wesley, 1984.

4. CHINN, P.L., WHEELER, C.E. Feminism and nursing. Nursing Outlook, St. Louis v.33, p.74-77, 1985.

5. COSTA, A.O., BARROSO, C., SARTI, C. Pesquisa sobre mulher no Brasil: do limbo ao gueto? Cadernos de Pesquisa. São Paulo: v. 54, p. 5-15, ago. 1985.

6. FERRETTI, C.J. A mulher e a escolha vocacional. Cadernos de pesquisa, São Paulo, v. 16, p.20-40, mar. 1976.

7. FREIRE, P. Pedagogia do Oprimido. Rio de Janeiro: Paz e Terra, 1978.

8. GERMANO, R.M. Educação e Ideologia na Enfermagem no Basil. São Paulo: Cortez, 1985.

9. HEDIN, B.A. A case study of oppressed group behavior in nurses. Image, v.18, n.2, p.53-57, 1986.

10. LEININGER, M.M. Caring: an essential human need. Thorqfare: Sclack, 1981.

11. __ Culture care diversity \&universality: a theory of nursing. New York: National League for Nursing Press, 1991.

12. LEWIN, H. Educação e força de trabalho feminista no Brasil. Cadernos de pesquisa, São Paulo, v. 32, p. $45-59$, fev. 1980.

13. LOPES, M.F. O trabalho da enfermeira: nem público nem privado - feminino e desvalorizado. Porto Alegre: PUC, 1987. Dissertação (Mestrado em Sociologia) - Instituto de Sociologia da Indústria, Pontifícia Universidade Católica do Rio Grande do Sul, 1987.

14. LOYOLA, C.D. Os doces corpos do hospital: os enfermeiros e o poder institucional na estrutura hospitalar. Rio de Janeiro: UFRJ, 1987.

15. NAKAMAE, D.D. Novos caminhos da Enfermagem: por mudanças no ensino e na prática da Profissão. São Paulo, Cortez, 1987.

16. RAMAZANOGLU, C. Feminism and the contradictions of opression. New York, Routledge, 1989.

17. ROBERTS, S.J. Opressed group behavior: implications for nursing. Advances in Nursing Science, Germantown, v. 5, p. 21 - 30, July 1983.

18. SAFFIOTI, H. Movimentos Sociais: face feminine. In: CARVAlHO, N.V. de (org.) A condição feminina, São Paulo: Vértice, 1988. Cap.9, p. 143 - 178.

19. SARTI, C. Feminismo no Brasil, uma trajetória particular. Cadernos de pesquisa, São Paulo: v. 64 , p. 38 - 47, fev. 1988.

20. SCHIRGER, M.F. Introspection: a prerequisite for emancipation. Nursing Forum, v. 17, n.3, p. 317-328, 1978.

21. SCOTT, J. Gênero, uma catgoria útil de análise histórica. Educação e realidade, Porto Alegre: v. 16, n.2, p. 5 -22, 1990.

22. SILVA, G.B. Enfermagem Profissional: análise crítica. São Paulo, Cortez, 1986.

23. THOMPSON, J.L. Critical Scholarship: the critique of domination in nursing. Advances in Nursing, Germantown: v. 10, n.1, p. $27-38,1987$.

24. TYLER, R. Basic principles of curriculum and instruction. Chicago: University of Chicago Press, 1949.

25. WALDOW, V.R. A opressão na Enfermagem: um estudo exploratório, In: M LOPES, M.J.M. et al. Gênero e Saúde. Porto Alegre: Artes Médicas, 1996. p. 106 - 132.

26. WATSON, J. Nursing human scienceand human care: a theory of nursing. Norwalk: Ct: Appleton-Century-Crofts, 1988.

27. WHEELER, C.E. e CHINN, P.L. Peace and power: a handbook of feminist process. New York: National League for Nursing, 1991.

28. YOUNG, I.M. Five faces of oppression. The philosophical forum, v.19, n.4, p. 270 - 289, Summer, 1988. 